\section{Commentary: Keeping it simple to avoid going commando}

\author{
Nels D. Carroll, MD, and Edward Y. Sako, MD, PhD
}

Burton and colleagues ${ }^{1}$ present an interesting solution to a challenging problem. At the onset, facing a patient whose prior aortic valve prosthesis and ascending graft have become grossly infected represents tremendous risk. Although encountered infrequently, the complexity of this problem warrants thoughtful reflection. The authors describe a patient whose infection has compromised both the aortic root and the mitral valve just 4 months after his index operation. Fortunately, the patient was hemodynamically stable and without overt signs of infection allowing for several days of optimization and planning before urgent intervention.

The strategy described is unique in that both valves are approached through an aortotomy. The potential benefits of this streamlined approach are intuitive, allowing for fewer suture lines and a potentially less complex, expedited procedure. What is less instinctive, but which the authors have previously demonstrated quite clearly, is their ability to produce adequate exposure and durable therapy. ${ }^{2}$

The native anatomy of the heart includes an intimate association of the fibrous aortic and mitral valve annuli bookended by the fibrous trigones. ${ }^{3}$ This component of the fibrous skeleton provides much of the structural integrity upon which the heart relies. When compromised by infection into these tissues, adequate repair depends on the durability of reconstruction. The authors have very cleverly utilized the rigidity provided by a stented bioprosthesis as an extension of the fibrous skeleton.

\footnotetext{
From the Department of Cardiothoracic Surgery, University of Texas Health Science Center at San Antonio, San Antonio, Tex.

Disclosures: Dr Sako has a financial relationship with Medtronic, Inc. Dr Carroll reported no conflicts of interest.

The Journal policy requires editors and reviewers to disclose conflicts of interest and to decline handling or reviewing manuscripts for which they may have a conflict of interest. The editors and reviewers of this article have no conflicts of interest.

Received for publication Aug 28, 2020; revisions received Aug 28, 2020; accepted for publication Sept 5, 2020; available ahead of print Sept 14, 2020.

Address for reprints: Edward Y. Sako, MD, PhD, Department of Cardiothoracic Surgery, University of Texas Health Science Center at San Antonio, Mail Code 7841, 7703 Floyd Curl Dr, San Antonio, TX 78229-3900 (E-mail: sako@uthscsa.edu). JTCVS Techniques 2020;4:103

2666-2507

Copyright (C) 2020 The Authors. Published by Elsevier Inc. on behalf of The American Association for Thoracic Surgery. This is an open access article under the CC BY-NCND license (http://creativecommons.org/licenses/by-nc-nd/4.0/).

https://doi.org/10.1016/j.xjtc.2020.09.006
}

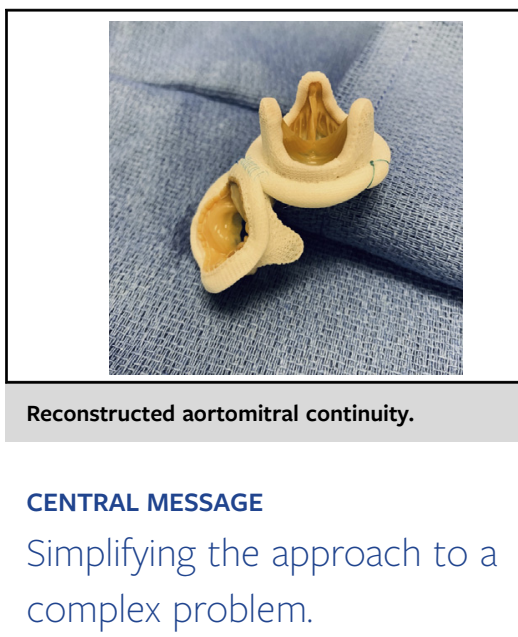

By placing a stented valve in the mitral position and utilizing its annular margin as a fixture point for the aortic bioprosthesis, they have restored much of the integrity of the fibrous skeleton. At the same time, partial fixation of these 2 rigid structures facilitates the dynamic hinge required by the cardiac cycle. They have accomplished this with a technique obviating an interposing reconstruction, as has been previously described. ${ }^{4}$

Surgical treatment of endocarditis is predicated on thorough debridement of infected tissue; therefore, reconstruction is dependent on the remaining viable tissue. It is important to note that in this case, "the tissue of the dome of the left atrium was intact" and the fibrous trigones were uninvolved. ${ }^{1}$

Because the degree of mitral valve destruction precluded repair, replacement with a bioprosthesis was necessary. It seemed reasonable to also replace the aortic valve with a bioprosthesis as opposed to a homograft in the interest of simplifying and expediting the operation.

The authors are to be commended for their successful repair of very complex anatomy. This represents an interesting solution to a problem that we all occasionally face, perhaps against our will. Having techniques such as this in our armamentarium might help to avoid going commando.

\section{References}

1. Elde S, de Biasi A, Woo YJ, Durton E. A novel alternative to the commando procedure: 1 constructing a neo-aortic root by anchoring to the sewing ring of the replaced mitral valve. J Thorac Cardiovasc Surg Tech. 2020;4:101-2.

2. Frederick JR, Woo YJ. Transaortic mitral valve replacement. Ann Thorac Surg. 2012;94:302-4.

3. Saremi F, Sanchez-Quintana D, Mori S, Muresian H, Spicer DE, Hassani C, et al Fibrous skeleton of the heart: anatomic overview and evaluation of pathologic conditions with CT and MR imaging. Radiographics. 2017;37:1330-51.

4. David TE, Kuo J, Armstrong S. Aortic and mitral valve replacement with reconstruction of the intervalvular fibrous body. J Thorac Cardiovasc Surg. 1997;114: 766-72. 